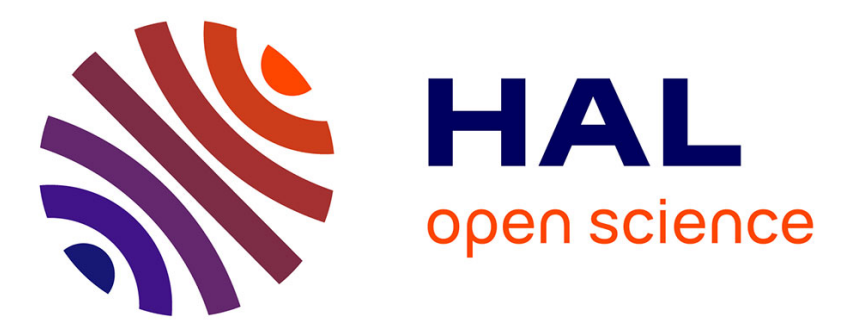

\title{
Surface temperatures of non-incubated eggs in great tits (Parus major) are strongly associated with ambient temperature
}

Marcel M. Lambrechts, Aude Caizergues, Charles Perrier, A. Charmantier, Samuel Caro

\section{To cite this version:}

Marcel M. Lambrechts, Aude Caizergues, Charles Perrier, A. Charmantier, Samuel Caro. Surface temperatures of non-incubated eggs in great tits (Parus major) are strongly associated with ambient temperature. International Journal of Biometeorology, 2020, 64 (10), pp.1767-1775. 10.1007/s00484020-01958-1 . hal-02899566

\section{HAL Id: hal-02899566 https: / hal.inrae.fr/hal-02899566}

Submitted on 15 Jul 2020

HAL is a multi-disciplinary open access archive for the deposit and dissemination of scientific research documents, whether they are published or not. The documents may come from teaching and research institutions in France or abroad, or from public or private research centers.
L'archive ouverte pluridisciplinaire HAL, est destinée au dépôt et à la diffusion de documents scientifiques de niveau recherche, publiés ou non, émanant des établissements d'enseignement et de recherche français ou étrangers, des laboratoires publics ou privés. 


\title{
Surface temperatures of non-incubated eggs in great tits (Parus major) are strongly associated with ambient temperature
}

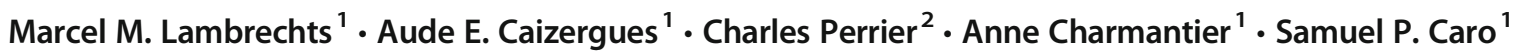

Received: 12 September 2018 / Revised: 17 June 2020 / Accepted: 19 June 2020

(C) ISB 2020

\begin{abstract}
Temperature is one of the best investigated environmental factors in ecological life-history studies and is increasingly considered in the contexts of climate change and urbanization. In avian ecology, few studies have examined the associations between thermal dynamics in the nest environment and its neighbouring air. Here, we placed avian nests and non-incubated eggs inside nest boxes at various air temperatures that ranged from 0.3 to $33.1^{\circ} \mathrm{C}$, both in the field and in laboratory conditions. We measured how the design of the boxes, their compass orientation and their location in more or less urbanized environments affected the surface temperature of nests and eggs. We also assessed whether covering the eggs with lining material influenced their surface temperature. Overall, across all performed tests, we found that the surface temperature of nests and eggs strongly reflected the air temperature measured outside of the nest boxes. While the design of the nest boxes had little influence on the temperature of nests and eggs, orienting the nest boxes to the north or to the west significantly decreased their surface temperature. The presence of lining material also kept eggs slightly warmer when air temperatures were low. Altogether these results suggest that nonincubated eggs are not well protected against extreme air temperatures prior to the onset of incubation. From an evolutionary point of view, producers of ectotherm eggs need therefore to time egg-laying appropriately in order to avoid unfavourable thermal nest environments.
\end{abstract}

Keywords Parus major $\cdot$ Ectotherm eggs $\cdot$ Nest temperature

\section{Introduction}

Temperature is amongst the most extensively investigated environmental factors in ecological life-history studies, especially since the recent overwhelming increase of the biological consequences of climate change (IPCC Report 2014; Gaughan et al. 2017). Temperature is also a rising concern

Electronic supplementary material The online version of this article (https://doi.org/10.1007/s00484-020-01958-1) contains supplementary material, which is available to authorized users.

Marcel M. Lambrechts

marcel.lambrechts@cefe.cnrs.fr

1 Centre d'Ecologie Fonctionnelle et Evolutive CEFE, UMR 5175, Campus CNRS, Université de Montpellier, Université Paul-Valéry Montpellier, EPHE, 1919 route de Mende, 34293 Montpellier Cedex 5, France

2 Centre de Biologie pour la Gestion des Populations UMR CBGP, INRAE, CIRAD, IRD, Montpellier SupAgro, Univ Montpellier, Montpellier, France in the field of urban ecology and urban evolutionary biology, with particular focus on the heat island effect of urbandwelling organisms (Bornstein 1968; Diamond and Martin 2020; Imhoff et al. 2010; Seress and Liker 2015). Long-term wildlife studies report associations between air temperature and reproductive performance (Visser et al. 2004; Mainwaring et al. 2017; Andreasson et al. 2018). Over evolutionary timescales, many species have evolved proximate responses to environmental factors in order to regulate reproductive functions, so that offspring are reared in optimal breeding conditions (Baker 1938). Breeding performance is therefore expected to be adjusted to changes in air temperature. In addition, breeding is often proximately inhibited by factors reflecting energetic constraints associated with extremely low air temperature (Glądalski et al. 2018).

The location and design of bird nests are expected to create a suitable micro-habitat for developing eggs and offspring, with suboptimal nest conditions adversely affecting breeding performance. Nest structure can influence the micro-climate surrounding the eggs (Britt and Deeming 2011; Crossman et al. 2011; Deeming et al. 2012; Mainwaring et al. 2012; 
Mainwaring et al. 2014; Heenan et al. 2015). Earlier studies also claimed that temperatures are higher and more stable inside nest chambers than outside of nests (Mainwaring et al. 2017). However, to our best knowledge, studies that quantitatively examined associations between the temperature of the nest environment and the temperature dynamics close to the nest remain rare (Gibb 1950; Kluijver 1950; Hafthorn 1981; Maziarz et al. 2017).

Here, we examine associations between surface temperatures of nests and non-incubated eggs from great tits (Parus major) placed inside nest boxes and external surface or air temperatures measured close to boxes. Surface temperatures of nests and eggs were first monitored in field conditions in boxes permanently attached to tree trunks and in which birds regularly breed (Fig. 1), both in forests and in urban areas including streets and parks. Urban areas consist in highly modified environments characterized by numerous new conditions such as high proportion of impervious surfaces, high concentrations in air pollutants as well as modified densities of trees (Gil and Brumm, 2014), which might affect egg temperature. We then used different set-ups in the laboratory to further explore the relationships between inside and outside temperatures over a large range of experimental conditions. In particular, the same set of boxes, nests and egg clutches were monitored both indoors and outdoors; in settings replicating more and less urbanized environments; in various compass directions; and with and without lining material protecting the eggs (Fig. 1). In this way, the same sets of nests and eggs were confronted with temperature regimes that might occur at different locations in the great tit distribution range, in natural and urbanized areas, or during different study periods in long-term studies throughout Europe. We predicted significant positive associations between surface temperatures measured inside the nest and surface or air temperatures measured outside the nest box. We also expected that the design of the boxes and their orientation would modulate these relationships.

\section{Methods}

We measured simultaneously surface temperatures inside nest boxes and surface or air temperatures around nest boxes in environmental conditions that varied in space and time. In the field, we measured the surface temperatures of box floors inside empty boxes, rims of nests, eggs and surface temperature of the tree trunk on which each box was placed (measured in the shade). In the laboratory, we measured the surface temperature of nest rim and eggs, and air temperatures within $1 \mathrm{~m}$ from the nests (Fig. 1). The measurements of air temperature were taken with an Ebro thermometer (TFH620, Ebro Electronic, Ingolstadt, Germany), whereas surface temperatures were measured with a Powertec Energy infrared thermometer (Kaleas, Denzlingen, Germany). To validate the values given by the two instruments, we correlated the air temperature measured in the shade close to the boxes with the Ebro thermometer, with the surface temperature of the front door of the same boxes with the Powertec thermometer. There was indeed a strong positive correlation between the

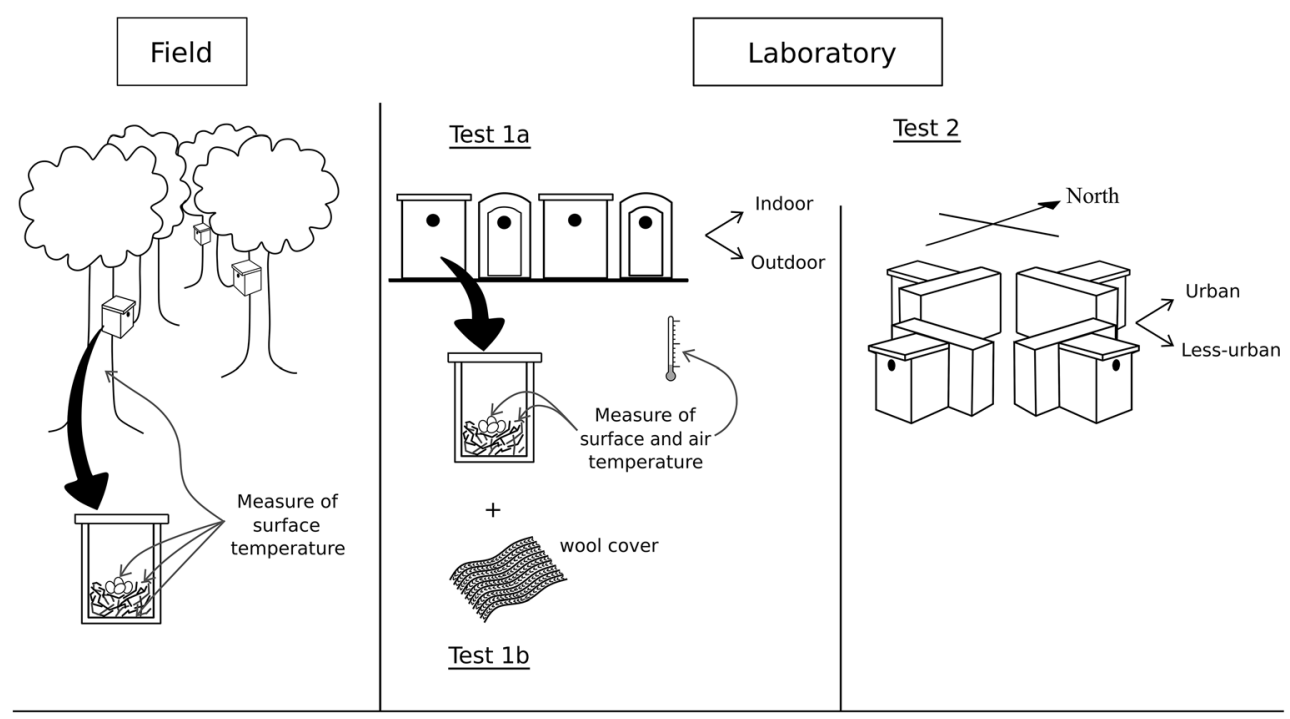

Fig. 1 Experimental design of the study of the influence of ambient temperature on unattended great tit (Parus major) nests and eggs. In the field, we assessed the relationships between the surface temperature of tree trunks and the surface temperature of (a) bottoms of empty nest boxes $(n=267)$, (b) nests that contained no eggs $(n=40)$ or (c) eggs $(n=27)$, in four types of boxes. In the laboratory, we related ambient air temperature with the temperature of great tit nests and eggs in two types of boxes, which (a) were placed in two environmental conditions (indoors vs. outdoors) (test 1a, $n=289$ ), (b) contained (or not) some lining material that covered the eggs (test $1 \mathrm{~b}, n=168$ ) or (c) were oriented in different compass directions, in two environmental conditions (urban vs. less urban) (test 2, $n=522$ ) 
two measurements (Pearson's correlation coefficient $r=$ 0.983, $n=197, p<0.001)$.

\section{Field study}

In the context of a long-term field study on great tits (Parus major), we monitored nest boxes in five geographically separated study plots within the urban area of Montpellier (Demeyrier et al. 2016; Lambrechts et al. 2017). A gradient of urbanization was measured in Demeyrier et al. (2016), integrating vegetation cover, artificial night lighting and air and noise pollutions within a 50-m-radius disk around each nest box. We provided three box types made from European larch (Larix decidua) that differed in the bottom surface (small, $6 \mathrm{~cm} \times 6 \mathrm{~cm}=36 \mathrm{~cm}^{2}$ vs. medium, $11 \mathrm{~cm} \times 11 \mathrm{~cm}=121$ $\mathrm{cm}^{2}$ vs. large, $14.5 \mathrm{~cm} \times 14.5 \mathrm{~cm}=210 \mathrm{~cm}^{2}$ ) and, by extension, differed in the volume of the nest chamber under the entrance hole $\left(648,2178\right.$ and $3780 \mathrm{~cm}^{3}$, respectively) (Lambrechts et al. 2017). In addition, we provided cylindrical wood-concrete Schwegler B1 boxes (internal diameter, $10.5 \mathrm{~cm}$ leading to a bottom area of ca. $113 \mathrm{~cm}^{2}$; volume of the nest chamber under the entrance hole, $1525 \mathrm{~cm}^{3}$ ), a box type used in long-term studies (Lambrechts et al. 2010).

The contents of the boxes were monitored with standardized protocols from the second half of March until mid-July. Briefly, monitoring consists in quantifying nest building activity (a few pieces of moss, crown of moss, nest without lining, nest with lining), measuring the height of the nest rim, counting the number of eggs, the number and estimated age of the chicks. These monitoring protocols have been applied for several decades in Mediterranean southern France (Blondel et al. 2006; Lambrechts et al. 2010; Demeyrier et al. 2016). Box contents, mainly egg sizes, and presence of nestlings and adults were also used to identify the breeding species (Blondel et al. 2006; Demeyrier et al. 2016).

During the 2017 breeding season (25 April-12 June 2017), we measured the surface temperature inside 106 boxes that were either empty, contained a nest but no eggs (nests measured before laying or after fledging) or contained a nest and non-incubated eggs (eggs prior to incubation or deserted eggs). During each box visit, we first measured the surface temperature of the trunk on which each box was placed (measures done in the shade). We then rapidly removed the front panel of the box to measure the surface temperature of (a) the internal box floor (in empty boxes), (b) the nest rim or (c) the eggs. Some boxes were measured on several occasions, in different days and/or at different breeding stages (with and without nests and eggs). We chose surface temperature of trunks as a measure of environmental temperature, instead of air temperature like in the laboratory experiments below, mainly to minimize disturbance time at the boxes that were occupied by breeding birds. Before opting for tree trunk surface temperature, we checked that it was well correlated with other kinds of surface (vegetation and box entrance, all $R^{2}>0.8, p<0.0001, n=424$ measures) and with ambient air ( $R^{2}=0.6, p<0.0001, n=72$ measures) temperatures.

\section{Laboratory experiments}

\section{General procedures}

In tits, the nest insulation capacity during incubation and after fledgling is positively correlated across nests that differ in size (Cruz et al. 2016), and does not differ significantly (Lambrechts et al., unpublished data). We collected six nests from first breeding attempts that were deserted during the nestling stage or after chicks had successfully fledged and we transferred them to the laboratory. The collected nests varied between 14 and $64 \mathrm{~g}$ (table S1). This variation in nest mass was larger than that reported in many field studies (Deeming and Mainwaring 2015).

The collected nests were inserted into two of the box types that were used for the field study (see above): three of the large wooden boxes made from Larix decidua (floor area $210 \mathrm{~cm}^{2}$, see above) and three wood-concrete boxes (floor area ca. $113 \mathrm{~cm}^{2}$, see above). Nests from the larger wooden boxes were substantially larger and heavier than nests from the smaller wood-concrete boxes (Lambrechts et al. 2017, table S1). In those experiments, box type therefore reflected not only differences in nest chamber design but also differences in nest size per se. All laboratory tests were conducted with the same six nests and six boxes. Positions of the boxes were alternated between successive temperature measurements, so that all individual boxes and box types had on average the same spatial position. Temperature was monitored with an interval of at least $1 \mathrm{~h}$ in between two successive measurements.

We also collected 30 eggs from deserted great tit nests in 2017 that were brought back to the laboratory and kept at room temperature before the start of the study. The eggs were randomly selected to constitute six 4-egg clutches that combined eggs from different nests of origin. A clutch size of four eggs per nest facilitated the measures of egg surface temperatures, and also allowed to control for a possible effect of clutch size on egg temperatures (Cooper et al. 2005; Nord and Nilsson 2012; Deeming and Reynolds 2015). Deserted eggs had different stages of development and included eggs with yolk and eggs with embryos. Because the thermic properties of eggs are associated with egg development (Cooper and Voss 2013), eggs were switched between boxes so that different boxes received the same eggs and/or the same clutches.

The associations between temperatures measured inside and outside the nest boxes were investigated in different conditions that are illustrated at Fig. 1. These conditions included comparisons of boxes placed indoors and outdoors (test 1a), 
with eggs that were or were not covered with wool (test 1b), and boxes that were placed in different compass directions (test 2), in more or less urbanized environments (test 2).

\section{Effect of indoor and outdoor environments on nest and egg temperatures (test 1a)}

In a set-up that controlled for box orientation, six boxes (three large wooden boxes and three wood-concrete boxes) were placed side by side with entrance holes all oriented in the same direction (N-E). Boxes and their nests were first at the Redon CNRS campus in Montpellier (indoors, 30 October-4 December 2017) and then transferred to a suburban garden at $15-\mathrm{km}$ flight distance from the Redon campus (outdoors, 5-11 December 2017) (test 1a on Fig. 1). Temperatures were monitored with an interval of at least $1 \mathrm{~h}$ between 6:30 and $22: 30$. Outdoor conditions reflected dynamic weather conditions with exposure to wind and sun and lower air temperatures, whereas indoor conditions reflected more stable conditions without wind and sun (one closed window not facing the sun) and higher air temperatures.

\section{Effect of lining material on egg temperatures (test 1b)}

In addition to comparing temperatures between indoor and outdoor conditions, we also examined the impact of lining material on surface temperatures of eggs. Great tits indeed cover unheated eggs with material, called lining material, which can be animal-based (hair, feathers, etc.) or artificial (for example, wool), depending on what is available around their territory (Kluijver 1950; Perrins 1979; Surgey et al. 2012). We monitored uncovered eggs (the same data as in test 1a) and the same eggs fully covered with a fabric of pure wool (thickness ca. $3.5 \mathrm{~mm}$, surface ca. $40 \mathrm{~cm}^{2}$ ) (7 sampling days; test $1 \mathrm{~b}$ on Fig. 1). We did not monitor nest rim temperatures as only eggs were covered by the wool fabric in this test.

\section{Effect of nest chamber orientation on nest and egg temperatures in more or less urbanized environments (test 2)}

Previous studies suggested that the orientation of the entrance hole exposes nest chambers to more or less sunshine and/or wind, which might influence the micro-climate inside the nest (Wilkin et al. 2007; Goodenough et al. 2008). To test the impact of box orientation on the micro-climate inside the box, we oriented the entrance holes of six boxes (three large wooden boxes and three wood-concrete boxes) in four compass directions (north, south, west, east) (Fig. 1). Compass directions were determined with a Pointe'S@t Optex device (Optex Electronique, Savines-le-Lac, France). All boxes from all compass directions were placed against a wooden beam (height $22 \mathrm{~cm}$, thickness $11.5 \mathrm{~cm}$ ) to simulate boxes attached to tree trunks. The presence of a wooden beam might prevent sunshine touching the boxes, depending on the time of the day. This experiment was repeated in two different set-ups, situated $30 \mathrm{~m}$ apart that simulated two different levels of urbanization. At one site (suburban area with ground covered with tiles and surrounded by pine trees and evergreen oaks, at $15 \mathrm{~km} \mathrm{~N}$-E from the Redon CNRS campus), six boxes were placed on a concrete table covered with tiles simulating a more urbanized environment (23-28 January 2018, 4 sampling days). At the other site (the same suburban garden, but on a spot covered with lawn and surrounded by pine trees and evergreen oaks), the same six boxes were placed on a wooden table on a natural soil simulating green space in a less urbanized environment (29 January-4 February 2018, 7 sampling days).

\section{Statistical analyses}

For field data, we applied mixed model procedures (type 3 tests of fixed effects; SAS 9.4, data not transformed) and ran three models with surface temperature of (a) internal box floor ( $n=267$ measures), (b) nest rim ( $n=40$ measures) or (c) non-incubated eggs (prior to incubation or deserted, $n=$ 27 measures) as dependent variables, and considered box type (four different box types: three wooden boxes of different sizes and one wood-concrete box) and surface temperature of the tree trunks as independent variables. Box identity (i.e. box number) and field site (five geographic areas) were added as random factors. Results of these tests are summarized in Table 1.

For laboratory data, we ran different models using the surface temperature of (a) the nest rim or (b) eggs, as dependent variables. For test 1a, location (indoors vs. outdoors), box type (wood vs. wood-concrete) and their interaction were used as fixed effects. We also ran two other models (one for each dependent variable) in which we replaced location (categorical variable) by the air temperatures measured outside of the box $(<1 \mathrm{~m}$ from nest) (continuous variable). For test $1 \mathrm{~b}$, we used the same main effects as those in test $1 \mathrm{a}$, added lining material (presence vs. absence of wool) and only used the twoway interactions that contained lining material (box type $\times$ lining and location $\times$ lining, or air temperature $\times$ lining). For test 2 , we used location (urbanized vs. less urbanized), box type (wood vs. wood-concrete), box orientation (compass directions $\mathrm{N}, \mathrm{E}, \mathrm{S}, \mathrm{W}$ ) and the two-way interactions involving box orientation (location $\times$ orientation and box type $\times$ orientation) as fixed effects. As for tests $1 \mathrm{a}$ and $1 \mathrm{~b}$, we also ran two tests in which location was replaced by the air temperatures measured outside of the box $(<1 \mathrm{~m}$ from nest). For all statistical tests, nest identity ( 6 different nests) and measure day (in Julian dates) were added as random factors. Non-significant interactions were removed from the models. Results of these laboratory tests are summarized in Table 2. 
Table 1 Effects of box type (wood small, wood medium, wood large, wood-concrete) and tree trunk surface temperature (measured in the shade) on surface temperatures of box floors $(n=267)$, nest rims $(n=40)$ and eggs $(n=27)$. Box identity and field site were included as random factors

\begin{tabular}{|c|c|c|c|c|c|c|}
\hline & \multicolumn{2}{|c|}{ Temp. box floors } & \multicolumn{2}{|c|}{ Temp. nest rims } & \multicolumn{2}{|c|}{ Temp. eggs } \\
\hline & $F$ values & $p$ values & $F$ values & $p$ values & $F$ values & $p$ values \\
\hline Trunk temp. & 2779.29 & $<0.001$ & 466.32 & $<0.001$ & 52.02 & $<0.001$ \\
\hline Box type & 2.02 & 0.117 & 0.92 & 0.411 & 2.17 & 0.163 \\
\hline
\end{tabular}

In bold are $\mathrm{p}$ values $<0.05$

\section{Results}

\section{Field study}

In the field, outside temperature varied between 8.2 and 33.1

${ }^{\circ} \mathrm{C}$. For each of the three mixed models that analysed separately the field data, surface temperatures measured on the tree trunks on which the boxes were attached strongly predicted the surface temperature of the box floors, nest rims, and eggs (all $p<0.001$, Table 1). Thus, surface temperatures of box floors, nests without eggs and non-incubated eggs were higher when outside surface temperatures were higher. In

temperatures of nest rims and eggs. Nest identity and day of measure were included as random factors. Non-significant interactions were removed from the statistical models
Table 2 Effects of location (indoors vs. outdoors in tests 1a [ $n=289]$ and $1 \mathrm{~b}[n=168]$; urban vs. less urban in test $2[n=522]$ ), box type (wood vs. wood-concrete), orientation (N, S, E, W), lining (presence vs. absence) and/or air temperature measured outside of the boxes, on surface

\begin{tabular}{|c|c|c|c|c|c|}
\hline & & \multicolumn{2}{|c|}{ Temp. nest rims } & \multicolumn{2}{|c|}{ Temp. eggs } \\
\hline & & $F$ values & $p$ values & $F$ values & $p$ values \\
\hline \multirow[t]{6}{*}{ Test 1a } & Location (indoor vs. outdoor) & 154.06 & $<0.001$ & 148.82 & $<0.001$ \\
\hline & Box type & 0.45 & 0.504 & 1.31 & 0.253 \\
\hline & Location $\times$ Box type & 0.25 & 0.614 & 0.71 & 0.401 \\
\hline & Air temp. & 2828.46 & $<0.001$ & 2314.28 & $<0.001$ \\
\hline & Box type & 1.91 & 0.169 & 7.56 & 0.006 \\
\hline & Air temp. $\times$ Box type & 1.54 & 0.216 & 3.00 & 0.085 \\
\hline \multirow[t]{10}{*}{ Test $1 b$} & Location (indoor vs. outdoor) & & & 139.28 & $<0.001$ \\
\hline & Box type & & & 1.43 & 0.233 \\
\hline & Lining & & & 0.06 & 0.814 \\
\hline & Location $\times$ Lining & & & 0.59 & 0.441 \\
\hline & Box type $\times$ Lining & & & 0.46 & 0.497 \\
\hline & Air temp. & & & 1742.06 & $<0.001$ \\
\hline & Box type & & & 4.41 & 0.036 \\
\hline & Lining & & & 8.38 & 0.004 \\
\hline & Air temp. $\times$ Lining & & & 7.93 & 0.005 \\
\hline & Box type $\times$ Lining & & & 0.94 & 0.334 \\
\hline \multirow[t]{10}{*}{ Test 2} & Location (urban vs. less urban) & 2.64 & 0.105 & 2.90 & 0.089 \\
\hline & Box type & 0.09 & 0.766 & 0.41 & 0.524 \\
\hline & Orientation & 2.64 & 0.049 & 1.37 & 0.251 \\
\hline & Location $\times$ Orientation & 0.96 & 0.411 & 0.68 & 0.567 \\
\hline & Box type $\times$ Orientation & 0.03 & 0.993 & 0.09 & 0.966 \\
\hline & Air temp. & 2023.80 & $<0.001$ & 1921.02 & $<0.001$ \\
\hline & Box type & 0.38 & 0.537 & 1.51 & 0.219 \\
\hline & Orientation & 11.99 & $<0.001$ & 5.54 & 0.001 \\
\hline & Air temp. $\times$ Orientation & 1.92 & 0.126 & 0.90 & 0.443 \\
\hline & Box type $\times$ Orientation & 0.75 & 0.522 & 0.47 & 0.702 \\
\hline
\end{tabular}

In bold are $\mathrm{p}$ values $<0.05$ 
those analyses, box type never influenced the temperature inside the boxes (all $p \geq 0.1$, Table 1).

\section{Laboratory experiments}

\section{Effect of indoor and outdoor environments on nest and egg} temperatures (test 1a)

During this test, nests and eggs were subjected to air temperatures that varied between 1.2 and $23.3^{\circ} \mathrm{C}$, with air temperatures that were approximately $10{ }^{\circ} \mathrm{C}$ higher in the indoor conditions than in the outdoor conditions. Surface temperatures of the nest rims and the eggs were strongly influenced by the location of the boxes ( $p<0.001$, Table 2$)$, with higher surface temperatures of nest rims and eggs measured indoors compared with outdoors. There was no effect of the type of nest box on nest rim and egg temperature in this model $(p>0.2$, Table 2). Replacing location by measured air temperature outside of the boxes led to similar results, except that in this analysis, eggs were found to be significantly cooler in large wooden boxes than in small wood-concrete boxes $(p=0.006$, Table 2).

\section{Effect of lining material on egg temperatures (test 1b)}

Similarly to results from test $1 \mathrm{a}$, the surface temperature of eggs was strongly influenced by the location of the boxes, with higher surface temperatures measured indoors compared with outdoors ( $p<0.001$, Table 2$)$. However, when location was replaced by the exact air temperature measured outside of the boxes, we also found that the effect of air temperature on egg temperature was modulated by the presence of lining material (interaction air temperature $\times$ lining, $p=0.005$ ). In particular, the presence of lining material kept eggs warmer at lower air temperatures (Fig. 2).

\section{Effect of nest chamber orientation on nest and egg temperatures in more or less urbanized environments (test 2)}

During test 2, nests and eggs were subjected to air temperatures that varied between 0.3 and $17.2^{\circ} \mathrm{C}$, with air temperature that was on average $3.5^{\circ} \mathrm{C}$ higher in the urban than in the less urban environment. Surface temperatures of nest rims and eggs were not reliably influenced by the location of the boxes (urban or less urban, Table 2), presumably because of the moderate $3.5^{\circ} \mathrm{C}$ temperature difference between the two sites. Nest box orientation however influenced the surface temperature of nest rims $(p=0.049)$, with cooler rims in boxes oriented to the north and west (mean \pm SD: north $=9.5 \pm 3.7^{\circ} \mathrm{C}$; west $=9.9 \pm 3.9{ }^{\circ} \mathrm{C}$; south $=10.5 \pm 4.5^{\circ} \mathrm{C}$; east $=10.7 \pm 4.1$ ${ }^{\circ} \mathrm{C}$ ). Replacing location by the exact air temperatures measured again confirmed that air temperature strongly influences surface temperature of nest rims and eggs (both $p<0.001$,
Table 2). In this analysis, the surface temperature of eggs was also influenced by the orientation of the boxes, with cooler eggs in boxes oriented to the north and west (mean \pm SD: north $=9.4 \pm 3.8{ }^{\circ} \mathrm{C}$; west $=9.7 \pm 3.8{ }^{\circ} \mathrm{C}$; south $=10.1 \pm$ $4.3^{\circ} \mathrm{C}$; east $=10.2 \pm 3.9^{\circ} \mathrm{C}$ ), like it was already the case for nest rims in the previous analysis.

\section{Discussion}

Avian populations are monitored in different locations at large spatial scales and are therefore exposed to different air temperature regimes that might influence local life-history decisions during the nesting period. However, the relative importance of nest placement and nest design influencing the thermal nest environment cannot be investigated when a nonmanipulated nest has a fixed spatial placement and is exposed to a localization-specific micro-climate. In our field and laboratory study, nests and eggs from a model species were exposed to different temperature regimes that varied between 0 and $33{ }^{\circ} \mathrm{C}$, covering temperatures that might occur in the species-specific Western Palaearctic distribution range (Harrison 1982). In addition, the same sets of nests and eggs were exposed to more stable indoor environments without wind and more dynamic outdoor environments with wind. This switch in environmental conditions simulated natural conditions where nests and eggs can suddenly be exposed to a drop in air temperature (Dhondt et al. 1983). Finally, in the laboratory conditions, nest placement was frequently changed so that nests with different designs had on average the same spatial position. In all settings, we found a close match between the surface temperatures of nests or eggs on the one hand and the temperatures measured outside the nest chambers on the other hand. Differences in temperatures of nests, eggs and air during a visit to a box were small compared with the huge fluctuations in temperature throughout the day and/or across days.

We expected that the placement and orientation of nests would influence the micro-climate inside nests. For instance, for nest chambers exposed to sunshine, we observed that eggs could occasionally be ca. $5^{\circ} \mathrm{C}$ above air temperature. This can be seen in Fig. 2, where the largest temperature differences between air and eggs occurred outdoors, especially in the few cases when nest boxes were exposed to the sun, while the lowest temperature variation occurred indoors where sun and wind were absent. The significant effects of location and orientation on the surface temperatures of nest rims and eggs were perhaps caused by different proximate underlying mechanisms. The simplest explanation is that heat produced by sunshine makes nest chambers warmer, and that exposure to sunshine, clouds or wind differed between sampling days, study locations and orientations of boxes. In addition, our outdoor study locations, which were less than $30 \mathrm{~m}$ apart, 
Fig. 2 Interaction between ambient air temperature and presence/absence of lining material on surface temperature of non-incubated great tit eggs. At low air temperatures, eggs are slightly warmer when covered with lining material. On the highest range of outdoor temperature, eggs sometimes become much warmer than air temperature (see "Discussion" for details). On the other hand, eggs can also sometimes be cooler than air temperature, presumably due to a short time-lag between egg temperature and warming air temperature in the morning. The black dashed and grey dotted lines are for illustration purposes only. The dashed line depicts the line of equality $(x=y)$, and the dotted line shows temperature measurements that were taken indoors and outdoors

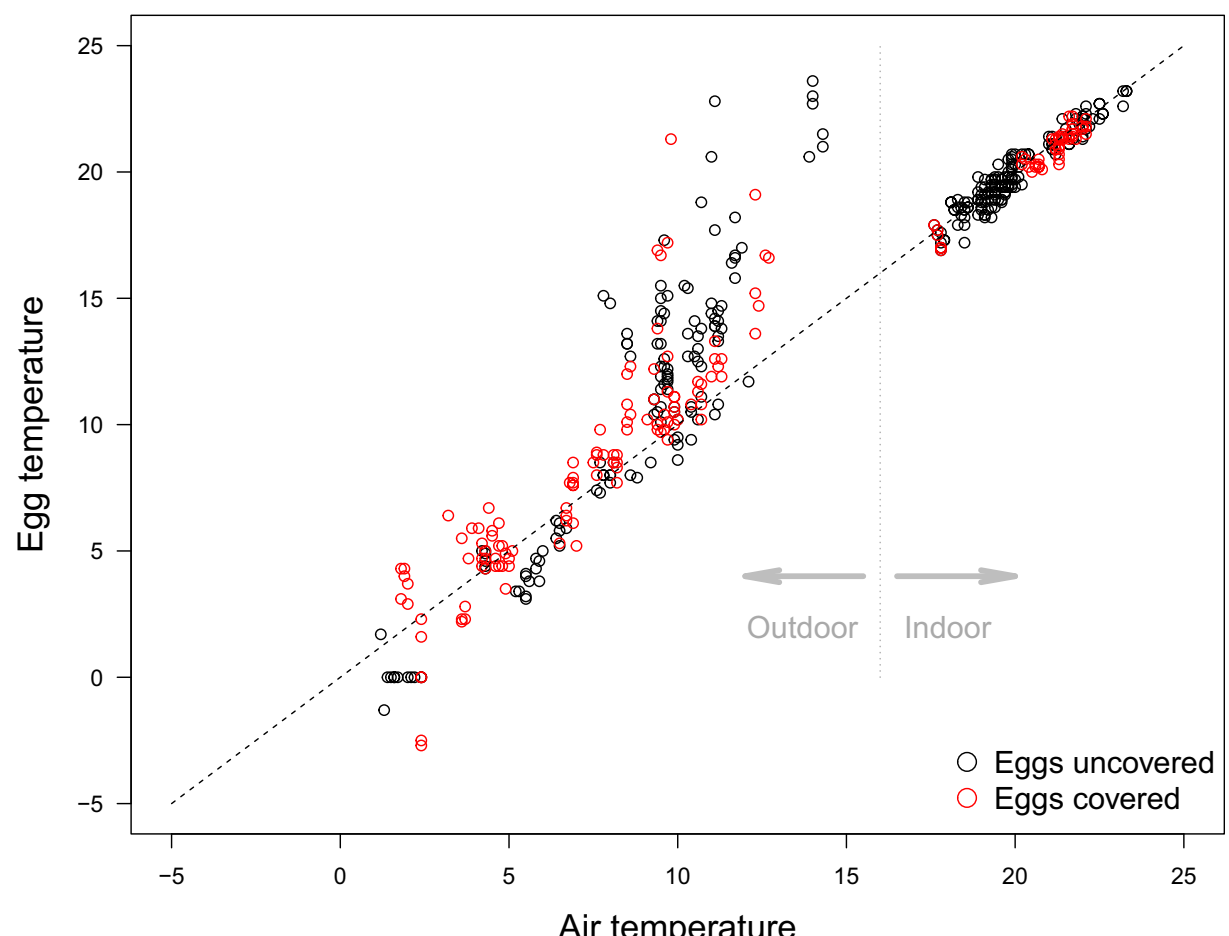

Air temperature differed in the placement and presence of evergreen tree canopy (Aleppo pine, Pinus halepensis, stone oak) so that the extent of exposure to sunshine differed between neighbouring locations. Future studies of micro-geographic variation in nest and egg temperatures therefore should focus not only on seasonal and yearly changes in local weather conditions but also on the micro-structure of the vegetation exposing nest chambers more or less to sunshine or shade. Different territories might therefore be exposed to different micro-climatic conditions and females might take these local micro-climatic conditions into account to adjust life-history decisions during the nesting season.

Surprisingly, we found that nest box type (and by extension nest size and mass) rarely influenced nest or egg temperatures. This would imply that prior to the onset of incubation, larger and heavier nests do not offer more efficient protection for eggs against extreme fluctuations in air temperature than smaller and lighter nests. What are the possible implications for how ectotherm eggs cope with aspects associated with cold spells or climate change? First, in great tits, Dhondt et al. (1983) reported that females do not start laying eggs until a cold spell is over, and Schaper et al. (2011) showed that a temperature increase is a trigger for the onset of egg-laying. Meijer et al. (1999) also showed that female European starlings (Sturnus vulgaris) need a temperature rise to initiate laying. In our study, we observed that eggs that are not protected by parents could freeze, whatever the size of the nest. When timing their reproduction, parents therefore not only have to anticipate favourable periods to rear offspring (cf. Baker 1938; Visser et al. 2004) but perhaps also need to avoid unfavourable periods for breeding, e.g. to prevent egg freezing or to reduce physiological costs of incubation in cold nest environments. Second, small passerines, like tits, cover their eggs with animal-based material during the egg-laying period (Kluijver 1950; Perrins 1979). Hiding eggs could be a protection strategy against nest predators but also might protect unheated eggs against low air temperatures. Although we found that eggs that were covered with a layer of wool were slightly warmer at low air temperatures, there was still a close match between the temperatures of the eggs and the air temperature outside the nest chamber (Fig. 2). This implies that hiding non-incubated eggs in the absence of the parents does not completely protect the eggs against important fluctuations in air temperature. Kluijver (1950, p 115-118) noticed that at night great tit females can sit on the lining material used to cover eggs before the onset of incubation. Night roosting on eggs during the egg-laying period has also been reported by Hafthorn (1981) and more recently by Pendlebury and Bryant (2005). This behaviour might in some conditions be a strategy to prevent egg freezing during the egg-laying period, especially at night when air temperatures and associated nest rim temperatures are low. In that case, the presence of a roosting female together with a layer of lining material and a thick nest could more strongly buffer the temperature decrease at night. Females may also sample surface temperatures prior to egglaying to reduce risks of egg freezing or risks associated with incubation in cold nest environments. This might explain why the nest construction period can last 2-3 weeks, despite the fact that females have the physical ability to construct a nest in a single or a few days (Lambrechts et al. 2012). 
To conclude, our results indicate that nests and their design, assumed to be adjusted to anticipate fluctuations in weather or changes in climate (Deeming et al. 2012; Mainwaring et al. 2012), do not protect unheated eggs against extreme fluctuations in air temperature. However, we do not exclude that nests are efficient tools to protect eggs against cold after the onset of incubation, e.g. to slow down egg cooling when females briefly leave incubated eggs. Responses of nests to cooling could be experimentally examined by exposing nests to a cold source (cf. Nager and van Noordwijk 1992) or a heat source (e.g. an infrared lamp), and quantify the dynamics of egg temperatures after exposure to cold or heat.

Acknowledgements This work was supported by the city of Montpellier, the University of Montpellier, OSU-OREME, and the Mediterranean Centre for Environment and Biodiversity (LabEx CeMEB). Nicolas Lambrechts helped with monitoring. We thank Arnaud Grégoire, Stéphanie Grosset, Thierry Noell, Pascal Pagano, Vincent Perret and Gilles Tessier for their logistic support. We thank three anonymous reviewers for their very constructive comments on earlier versions of this manuscript.

\section{References}

Andreasson F, Nord A, Nilsson J-A (2018) Experimentally increased nest temperature affects body temperature, growth and apparent survival in blue tit nestlings. J Avian Biol e01620. https://doi.org/10.1111/ jav.01620

Baker JR (1938) The evolution of breeding seasons. In: De Beer GR (ed) Evolution: essays on aspects of evolutionary biology. Oxford University Press, London, pp 161-177

Blondel J, Thomas DW, Charmantier A, Perret P, Bourgault P, Lambrechts MM (2006) A thirty-year study of phenotypic and genetic variation of blue tits in Mediterranean habitat mosaics. BioScience 56:661-673

Bornstein RD (1968) Observations of the urban heat island effect in New York City. J Appl Meteorol 7(4):575-582

Britt J, Deeming DC (2011) First-egg date and air temperature affect nest construction in blue tits Cyanistes caeruleus, but not in great tits Parus major. Bird Study 58:78-89

Cooper CB, Voss MA (2013) Avian incubation patterns reflect temporal changes in developing clutches. PLoS One 8(6):e65521. https://doi. org/10.1371/journal.pone.0065521

Cooper CB, Hochachka WM, Butcher G, Dhondt AA (2005) Seasonal and latitudinal trends in clutch size: thermal constraints during laying and incubation. Ecology 86:2018-2031

Crossman CA, Rohwer VG, Martin PR (2011) Variation in the structure of bird nests between Northern Manitoba and Southeastern Ontario. PLoS One 6(4):e19086. https://doi.org/10.1371/journal.pone. 0019086

Cruz Á, Álvarez A, Barba E (2016) Nest insulation capacity during incubation and after fledgling are related. Avian Biol Res 9:22-27

Deeming DC, Mainwaring MC (2015) Functional properties of nests. In: Deeming DC, Reynolds SJ (eds) Nests, eggs, and incubation: new ideas about avian reproduction. Oxford University Press, Oxford, pp $29-49$

Deeming DC, Reynold SJ (2015) Nests, eggs, and incubation: new ideas about avian reproduction. Oxford University Press, Oxford
Deeming DC, Mainwaring MC, Hartley IR, Reynolds SJ (2012) Local temperature and not latitude determines the design of blue tit and great tit nests. Avian Biol Res 5:203-208

Demeyrier V, Lambrechts MM, Perret P, Grégoire A (2016) Experimental demonstration of an ecological trap for a wild bird in a man-transformed environment. Anim Behav 118:181-190

Dhondt AA, Eykerman R, Hublé J (1983) Laying interruptions in tits Parus spp. Ibis 125:370-376

Diamond SE, Martin RA (2020) Evolutionary consequences of the urban heat island. In: Szulkin M, Munshi-South J, Charmantier A (eds) Urban evolutionary biology. Oxford University Press, Oxford. https://doi.org/10.1093/oso/9780198836841.003.0006

Gaughan JB, Lees AM, Sejian V (2017) Sixty years of animal biometeorology. Int J Biometeol. https://doi.org/10.1007/s00484-0171459-1

Gibb J (1950) The breeding biology of the great and blue titmice. Ibis 92: 507-539

Gil D, Brumm H (2014) Avian urban ecology. Oxford University Press, Oxford

Glądalski M, Bańbura M, Kaliński A, Markowski M, Skwarska J, Wawrzyniak J, Zieliński Z, Bańbura J (2018) Hatching delays in great tits and blue tits in response to an extreme cold spell: a longterm study. Int J Biometeol. https://doi.org/10.1007/s00484-0181541-3

Goodenough AE, Maitland DP, Hart AG, Elliot SL (2008) Nestbox orientation: a species-specific influence on occupation and breeding success in woodland passerines. Bird Study 55:222-232

Hafthorn S (1981) Incubation during the egg-laying period in relation to clutch-size and other aspects of reproduction in the great tit Parus major. Ornis Scand 12:169-185

Harrison C (1982) An atlas of the birds of the Western Palaearctic. Collins, London $322 \mathrm{pp}$

Heenan CB, Goodman BA, White CR (2015) The influence of climate on avian nest construction across large geographic gradients. Glob Ecol Biogeogr 24:1203-1211

Imhoff ML, Zhang P, Wolfe RE, Bounoua L (2010) Remote sensing of the urban heat island effect across biomes in the continental USA. Remote Sens Environ 114:504-513. https://doi.org/10.1016/j.rse. 2009.10.008

IPCC Report on Climate Change (2014) Synthesis Report. In: Core Writing Team, Pachauri RK, Meyer LA (eds) Contribution of working groups I, II and III to the Fifth Assessment Report of the Intergovernmental Panel on Climate Change. IPCC, Geneva $151 \mathrm{pp}$

Kluijver HN (1950) Daily routines of the great tit, Parus m. major L. Ardea 38:99-135

Lambrechts MM, Adriaensen F, Ardia DR, Artemyev A, Atiénzar F, Bańbura J, Barba E, Bouvier J-C, Camprodon J, Cooper CB, Dawson RD, Eens M, Eeva T, Faivre B, Garamszegi LZ, Goodenough AE, Gosler AG, Grégoire A, Griffith SC, Gustafsson L, Scott Johnson L, Kania W, Keišs O, Llambias PE, Mainwaring MC, Mänd R, Massa B, Mazgajski TD, Møller AP, Moreno J, NaefDaenzer B, Nilsson J-A, Norte AC, Orell M, Otter KA, Park CR, Perrins CM, Pinowski J, Porkert J, Potti J, Remeš V, Richner H, Rytkönen S, Shiao M-T, Silverin B, Slagsvold T, Smith HG, Sorace A, Stenning MJ, Stewart I, Thompson CF, Török J, Tryjanowski P, van Noordwijk AJ, Winkler DW, Ziane N (2010) The design of artificial nestboxes for the study of secondary hole-nesting birds: a review of methodological inconsistencies and potential biases. Acta Ornithol 45:1-26

Lambrechts MM, Aimé C, Midamegbe A, Galan M-J, Perret P, Grégoire A, Doutrelant C (2012) Nest size and breeding success in first and replacement clutches: an experimental study in blue tits Cyanistes caeruleus. J Ornithol 153:173-179

Lambrechts MM, Charmantier A, Demeyrier V, Lucas A, Perret S, Abouladzé M, Bonnet M, Canonne C, Faucon V, Grosset S, le Prado G, Lidon F, Noell T, Pagano P, Perret V, Pouplard S, 
Spitaliéry R, Bernard C, Perret P, Blondel J, Grégoire A (2017) Nest design in a changing world: great tit Parus major nests from a Mediterranean city environment as a case study. Urban Ecosyst 20:1181-1190. https://doi.org/10.1007/s11252-017-0670-5

Mainwaring MC, Hartley IR, Bearhop S, Brulez K, du Feu CR, Murphy G, Plummer KE, Webber SL, Reynolds SJ, Deeming DC (2012) Latitudinal variation in blue tit and great tit nest characteristics indicates environmental adjustment. J Biogeogr 39:1669-1677

Mainwaring MC, Hartley IR, Lambrechts MM, Deeming DC (2014) The design and function of birds' nests. Ecol Evol 20:3909-3928

Mainwaring MC, Barber I, Deeming DC, Pike DA, Roznik EA, Hartley IR (2017) Climate change and nesting behaviour in vertebrates: a review of the ecological threats and potential for adaptive responses. Biol Rev 92:1991-2002

Maziarz M, Broughton RK, Wesołowski T (2017) Microclimate in tree cavities and nest-boxes: implications for hole-nesting birds. For Ecol Manag 389:306-313

Meijer T, Nienaber U, Langer U, Trillmich F (1999) Temperature and timing of egg-laying of European starlings. Condor 101:124-132
Nager RG, Noordwijk van AJ (1992) Energetic limitation in the egglaying period of great tits. Proc R Soc B 249:259-263

Nord A, Nilsson J-A (2012) Context-dependent costs of incubation in the pied flycatcher. Anim Behav 84:427-436

Pendlebury CJ, Bryant DM (2005) Night-time behaviour of egg-laying tits. Ibis $147: 342-345$

Perrins CM (1979) British tits. Collins, London

Schaper SV, Dawson A, Sharp PJ, Gienapp P, Caro SP, Visser ME (2011) Increasing temperature, not mean temperature, is a cue for avian timing of reproduction. Am Nat 179:E55-E69

Seress G, Liker A (2015) Habitat urbanization and its effects on birds. Acta Zool Acad Sci Hung 61(4):373-408

Surgey J, du Feu CR, Deeming DC (2012) Opportunistic use of a woollike artificial material as lining of tit (Paridae) nests. Condor 114: 385-392

Visser ME, Both C, Lambrechts MM (2004) Global climate change leads to mistimed avian reproduction. Adv Ecol Res 35:89-110

Wilkin TA, Perrins CM, Sheldon BC (2007) The use of GIS in estimating spatial variation in habitat quality: a case study of lay-date in the great tit Parus major. Ibis 149:110-118 